Bond University

Research Repository

\title{
Room service in a public hospital improves nutritional intake and increases patient satisfaction while decreasing food waste and cost
}

\author{
McCray, S; Maunder, K; Barsha, L; Mackenzie-Shalders, K
}

Published in:

Journal of Human Nutrition and Dietetics

DOI:

10.1111/jhn. 12580

Licence:

Other

Link to output in Bond University research repository.

Recommended citation(APA):

McCray, S., Maunder, K., Barsha, L., \& Mackenzie-Shalders, K. (2018). Room service in a public hospital improves nutritional intake and increases patient satisfaction while decreasing food waste and cost. Journal of Human Nutrition and Dietetics, 31(6), 734-741. https://doi.org/10.1111/jhn.12580

\section{General rights}

Copyright and moral rights for the publications made accessible in the public portal are retained by the authors and/or other copyright owners and it is a condition of accessing publications that users recognise and abide by the legal requirements associated with these rights.

For more information, or if you believe that this document breaches copyright, please contact the Bond University research repository coordinator 
4 Abstract

5 Background

6 Room service (RS) is a hospital foodservice model that is traditionally unique to the private sector.

It allows patients to order meals compliant to their nutritional requirements from a single integrated menu at a time that suits them. Meals are prepared and delivered within 45 minutes of order.

9 Following implementation in a private adult facility in 2013, Mater Group implemented the first RS

10 in a public adult facility in Australia in 2016. In a pre-post study comparing RS with a traditional

11 foodservice model (TM), key outcomes were measured and analysed.

\section{Methods}

13 A retrospective analysis of quality assurance data audits in a pre- post study design was undertaken

14 to assess patient nutritional intake, plate waste, satisfaction, and meal costs before and after RS

15 implementation.

16 Results

17 Comparison of nutritional intake between TM $(n=84)$ and RS $(n=103)$ showed statistically

18 significant increases with RS in both energy (5513 kJ/day vs. $6379 \mathrm{~kJ} /$ day, $\mathrm{p}=0.020)$ and protein

$19(53 \mathrm{~g} /$ day vs. $74 \mathrm{~g} / \mathrm{day}, \mathrm{p}<0.001)$ intake, as well as energy and protein intake as a percentage of

20 requirements $(64 \%$ vs. $78 \%, p=0.002$ and $70 \%$ vs. $99 \%, p<0.001$ respectively). Total average plate

21 waste decreased from $30 \%$ to $17 \%(\mathrm{p}<.001)$. Patient satisfaction indicated an improvement with RS,

22 with $98 \%$ of patients scoring the service good to very good, compared with $75 \%$ for $\mathrm{TM}(\mathrm{p}<0.04)$.

23 Patient food costs decreased by $28 \%$ per annum with RS.

\section{Conclusions}

25 This research provides insight into the benefits achievable with RS in the public hospital setting,

26 confirming that a patient-centered food service model can cost-effectively improve clinical

27 outcomes. 
29 Room service (RS) is a foodservice model that has been adopted within the private acute care setting over the past 15 years, driven by a focus on improving patient satisfaction and reducing food waste $^{(1-3)}$. Hospital food service provision is increasingly being scrutinized in the cost constrained and patient centred healthcare environment to reduce costs, as well as to reduce the environmental impact of foodservice waste $\left.{ }^{(4-6}\right)$. Patient centred foodservice models which enable patient engagement and a personalised service can contribute to improvements in overall patient satisfaction $^{(7-9)}$. Patient experience is also linked to the delivery of high quality care $\left.{ }^{(10}\right)$.

Malnutrition is a well-documented clinical issue associated with negative clinical outcomes and healthcare $\operatorname{costs}^{(11-14)}$, and poor nutritional intake is also recognised as a risk factor for poor patient outcomes and hospital mortality ${ }^{(13,15)}$. Meeting patients' nutritional requirements in an acute care setting is difficult with several extenuating factors including patients' appetite and clinical symptoms, food access and availability, menu quality, food choice and individual patient preferences $^{(16)}$. Therefore, there is a focus on hospital foodservices to potentially increase patients' nutritional intake. To date, menu strategies to improve intake have included use of oral nutrition supplements $^{(17,18)}$, fortification of menu items in terms of protein and energy and use of protein and energy dense snacks between main meal service ${ }^{(19)}$. Whilst these have been shown to be clinically effective ${ }^{(17,20)}$, the potential for increase in costs and poor compliance are seen as barriers to their use $^{(17)}$. Other strategies have focussed on the meal environment, presentation ${ }^{(21,22)}$ and patients' access to meals such as protected meal times ${ }^{(16,23)}$ to allow patients adequate and uninterrupted time to consume their meals. Further strategies have addressed food ordering and delivery processes in an attempt to ensure that patients have adequate choice and are able to make their choice close to meal times. These include bulk trolley service models ${ }^{(8)}$, electronic bedside ordering ${ }^{(24,25)}$ and emenus $^{(26)}$

Following the implementation of room service in Australia in their private adult facility in 2013, the Mater Group demonstrated improvements in key outcome measures nutritional intake, plate waste, patient satisfaction and patient meal costs with the RS model ${ }^{(27)}$. This study aimed to repeat the measurement of these key outcomes in a public setting, following the implementation of RS in their

\section{Methods}

61 Mater Hospital Brisbane (MHB) is a 126 bed public acute care adult hospital with a case mix of patients, designated into general medical, surgical and oncology wards. The organisation's annual 
malnutrition point prevalence audit data shows malnutrition prevalence rates for MHB at $32 \%$ in 2014 and 33\% for 2017. In 2016 MHB transitioned from a Traditional Model (TM) to RS, using the CBORD ${ }^{\circledR}$ Food and Nutrition Solutions (FNS), and Room Service Choice ${ }^{\mathrm{TM}}(\mathrm{v} 10.12 .100)^{(28)}$ software. In TM, patients ordered their meals by completing a paper menu (cook fresh, 14 day cycle menu) up to 24 hours prior to meals which were then collected at a set time by Nutrition Assistant staff. Meals were delivered at set meal times during the day: breakfast between 0630-0730 hours; lunch between 1145-1245 hours; and dinner between 1700-1800 hours. In RS, patients order meals from a single integrated a la carte style menu anytime between 0630-1900 hours by phoning RS representatives in a central call centre. Meals are prepared on demand and aim to be delivered within 45 minutes of receiving the order. Menus for both RS and TM were analysed in FNS for nutritional quality and to ensure compliance to therapeutic diets according to the New South Wales (NSW) Agency for Clinical Innovation Nutrition Standards for Adult Inpatients and the Queensland Health Nutrition Standards for Meals and Menus ${ }^{(29,30)}$.

A retrospective analysis of routinely collected quality assurance data in a pre-post study design measured nutritional intake, plate waste, patient satisfaction, and overall patient meal costs at MHB to enable a comparison of TM (pre-implementation) in August 2014 and RS (post-implementation) in March 2017. Data collection process and tools utilised were the same for both TM and RS cohorts.

The Mater Health Human Research Ethics Committee assessed this project as exempt from requiring ethical approval. As a retrospective analysis of de-identified routine audit data, it did not meet the definition of research in accordance with the [Australian] National Statement on Ethical Conduct in Human Research ${ }^{(31)}$.

\section{Nutritional Intake and Plate Waste}

Nutritional intake and plate waste data was collected by University nutrition and dietetics students during their food service internship placements. Data collection was supervised by the nutrition and dietetics department's senior clinical educator, senior foodservices dietitian and director of nutrition and dietetics as part of the quality assurance process. Students were provided one day of training in the data collection methodology and use of the tool by the senior clinical educator and were assessed in the use of the tool to ensure accuracy and uniformity of data collection between auditors. During these audits, patient demographic data including age, sex, weight and height was obtained via hospital records. Standardised food portions are served to the patient, managed through the use of FNS standardised recipes and serving sizes, and are audited monthly. A meal intake 
observation tool using a 5 point visual scale $(0,1 / 4,1 / 2,3 / 4$, all) was used to record the volume of each meal consumed by the patient ${ }^{(32)}$. FNS contains the menu items, weights of the standardised portion sizes and their nutritional composition per patient order and therefore can automatically calculate the nutritional composition of menu items recorded as eaten. All of the edible components of items ordered were evaluated, excluding bottled water due to its nil contribution to energy and protein intake. Audits were undertaken over a four day period in August 2014 for TM and March 2017 for RS. Patients were excluded if they were classified as NBM (nil by mouth), restricted to fluids only, on enteral or parenteral nutrition, less than 18 years old, critically ill or palliative, did not have a weight recorded or had less than $24 \mathrm{hr}$ consecutive intake data.

Total nutritional intake including all meals and snacks was recorded across a minimum 24 hour consecutive period to determine energy (in kilojoules) and protein (in grams) intake for individual patients per day. Nutritional analysis was performed using CBORD ${ }^{\circledR}$ FNS version v10.12.100 ${ }^{(33,34)}$ which contains the AusNut Special Edition nutrient database (1999) ${ }^{(35)}$. The patient's weight was used to estimate their energy and protein requirements by subgroup: medical $(30 \mathrm{kcal} / \mathrm{kg} ; 1.0 \mathrm{~g} / \mathrm{kg}$ protein), surgical (30 kcal/kg; 1.2g/kg protein) and oncology (32 kcal $/ \mathrm{kg} ; 1.35 \mathrm{~g} / \mathrm{kg}$ protein). Where BMI $>30 \mathrm{~kg} / \mathrm{m}^{2}$, Adjusted Ideal Body Weight was used to calculate these requirements to reflect current clinical practice on the wards ${ }^{(36-42)}$. A comparison was then made to assess percentage of protein and energy consumed against estimated energy requirements (EER) and estimated protein requirements (EPR).

Plate waste was recorded across a minimum 24 hour consecutive period including all meals and snacks by evaluating each of the individual food items remaining on the plate and calculating

\section{Patient Satisfaction}

124 Patient satisfaction was measured using the Acute Care Hospital Foodservice Patient Satisfaction 125 Questionnaire (ACPHFSQ) ${ }^{(43)}$. Patients were excluded if they were asleep at the time of data 126 collection, refused the survey or were requested by nursing staff to not be included. Data for both surveys was collected in a one day snapshot in August 2014 for TM and March 2017 for RS.

Patient Meal Costs

130 Total patient food costs were obtained from the foodservice department end of month finance

131 expense reports. TM data was analysed for the 12-month period from January to December 2014 and RS data for the 12-month period from January to December 2017. Patient meal costs were 
133 calculated and compared as patient food cost per patient occupied bed day (OBD). OBD's were

134 calculated for each 12 month period. Australian annual average inflation rate for food for the period 135 2014-2017 was 1.4\% per annum and was considered when evaluating overall patient meal cost data 136 for this period ${ }^{(44)}$

\section{Data Analysis}

139 Statistical analysis of data was completed using SPSS software ${ }^{(45)}$. Normality checks were 140 completed using histograms and Q-Q box plots with the Shapiro-Wilk test used as required.

141 Independent t-tests were used to analyse pre and post data for age, weight, BMI, estimated energy 142 and protein requirements (EER and EPR), estimated energy and protein intakes (EEI and EPI) and 143 plate waste. A Pearson chi-square method was used to analyse pre and post data on gender, cohort 144 split (medical, oncology and surgical) for nutritional intake versus requirements and patient satisfaction. Significance was assessed at $\mathrm{p}<0.05$.

\section{Results}

Nutritional Intake and Plate Waste

149 Nutritional intake and plate waste data was collected for 84 patients for TM and 103 patients for RS. There were significant differences between the TM and RS participant demographics of age, weight and medical classification. There were no significant differences between TM and RS cohort in regards to gender. Despite some differences to participant demographics, no significant differences in the estimated energy or protein requirements were calculated between the patient cohorts (Table 1). After the introduction of RS, average energy intake, protein intake, \% of EER and \% EPR all increased significantly from TM values $(p=0.020, p<0.001, p=0.002, p<0.001$ respectively) (Table 2). When analysed by subgroups medical, surgical and oncology, there was a significant increase in average energy intake and \% EER in the surgical group. All sub groups showed a significant increase in average protein intake and oncology and surgical subgroups showing a significant increase in \% EPR (Table 3).

Plate waste data included a total of 4141 individual food items served to 84 patients in TM in comparison to 2332 individual food items served to 103 patients in RS. Overall, the average plate waste significantly decreased from $30 \%$ to $17 \%$ ( $p<0.001)$.

\section{Patient Satisfaction}

166 A total of 20 patients completed the ACHFPSQ ${ }^{(43)}$ for TM and 42 patients completed for RS. There was no significant difference between groups in age, gender or medical classification. Overall the 
percentage of patients rating their overall satisfaction with the foodservice as 'very good' or 'good' increased from $75 \%$ for TM participants to $98 \%$ for RS participants $(\mathrm{p}=0.040$ ).

Patient Meal Costs

172 Compared to the 12 month period for TM, total patient meal costs were decreased by $28 \%$ for an

173 equivalent 12 month period for RS. Total staffing (full-time equivalent levels) required for TM and 174 RS remained the same.

\section{Discussion}

177 Research supporting positive outcomes from the implementation of RS to date has been in private hospital settings and it is often seen as an option in the private healthcare sector only. This study demonstrated improvements across key outcome measures in the public hospital setting, thus demonstrating that this model has value across both public and private environments.

RS is designed to allow patients to order food that they desire (within therapeutic diet compliance limits) when they desire, leading to the expectation that they will eat a greater proportion of what they order, waste less and have greater satisfaction with their hospital foodservice experience. Similar to recent findings in the private hospital setting ${ }^{(27)}$, this study found statistically significant increases in both total energy and protein intake as well as intake in energy and protein as a percentage of requirements were seen with the implementation of RS as compared with TM. This finding is important as hospitals continue to investigate strategies to assist patients to maximise their intake with poor food intake recognised as a risk factor for negative and costly clinical and hospital outcomes ${ }^{(13,15-17)}$. These strategies usually focus on individual points in the foodservice process such as menu quality and supplementation ${ }^{(17-19)}$, menu choice ${ }^{(22)}$, meal environment ${ }^{(16,21,23)}$ and ordering and delivery processes ${ }^{(8,24,26)}$. RS delivers on all of these strategies providing a wide range of high nutritional quality menu items at flexible times throughout the day via an engaging patient-centric ordering process. The British Dietetic Association supports a 'food first' approach recommending the improvement of nutritional status via ordinary food as a first step in providing nutritional support ${ }^{(17)}$ and the RS cook on demand model allows flexibility for meals to be tailormade to a patient's individual needs in an aim to achieve this. A single integrated a la carte style menu available throughout the day allows items that may traditionally only be available at certain meal times (such as scrambled eggs at breakfast), to be ordered anytime according to patient preferences, taste and appetite. The "build your own" concept applied to items such as sandwiches, pizzas and omelettes allows greater menu personalisation. Oncology patients often experience poor appetite, feelings of nausea and regular taste changes due to disease and treatments and therefore 
203 being able to order food items that suit their immediate appetite and preferences may assist in both

204 their nutritional intake as well as improve their overall experience of foodservice ${ }^{(46-48)}$. Many medical and surgical patients miss set meal times due to tests and procedures, surgery schedules and fasting protocols. Having the ability to order food at times that suit their appetite and clinical schedule may improve both intake and satisfaction with the meal service ${ }^{(16,17)}$. The provision of regular hospital snacks is also a strategy used for patients who prefer to eat little and often ${ }^{(49)}$ and a lack of hospital snack provision has been identified as an inhibitory factor of optimal nutrition ${ }^{(17)}$.

210 The order on demand nature of RS allows for this with no limit on number of times that patients can 211 order throughout the day.

213 Plate waste is reported between $20-40 \%$ in traditional pre-plated meal models ${ }^{(4)}$. This study saw an 214 overall reduction in plate waste with RS to $17 \%$, similar to a previous RS study which reported 215 average plate waste of $12 \%{ }^{(27)}$. Bulk service systems including buffet trolleys whereby patients 216 choose what they feel like at set meal times have reported left over waste of up to $50 \%{ }^{(4,50)}$. The 217 cook on demand model is expected to reduce production waste as only items that are ordered are 218 produced compared to bulk cook in advance models which rely on a degree of forecasting.

219 Production waste was not measured in this study but total food costs were significantly less, and a proportion of this is likely due to reductions in total food production. Future research should include measures of production waste when comparing models.

Food provision may be considered an important aspect in mitigating anxiety, stress and suffering of a patient in a hospital environment ${ }^{(2)}$. Improved patient satisfaction has been consistently reported in the literature as a major benefit of RS in the private setting ${ }^{(1,2,27)}$ and this was also seen in this study in the public setting. While patient satisfaction could be considered high in TM, this increased to $98 \%$ of patients reporting the food service as good to very good for RS. The improvement in patient satisfaction with RS may be due to the flexibility for patients to order what and when they feel like eating and in amounts and combinations that they feel like, enabling greater control in meal choices plus increased interaction and engagement in the meal order process when compared to TM. A key point of difference in RS compared to the TM model is the elimination of structured meal times, focusing the hospital's meal service around the patient's clinical treatment schedule, rather than being driven by the organization's operational meal production schedule.

Ordering via the call centre or meal order staff at the bedside facilitated increased patient-staff interactions and greater patient engagement, as compared to the traditional paper menu ordering model in this study. Increased patient engagement in the meal order process has been demonstrated 
238 in other foodservice interventions such as an electronic bedside menu ordering system ${ }^{(24)}$ and bulk

239 trolley service models whereby patients have significant interaction with meal staff to assist them to 240 choose items best suited to their preferences and requirements ${ }^{(8)}$. It has been suggested that patients

241 benefit from support with respect to making the most appropriate choices and that healthcare 242 professionals have the responsibility to facilitate this ${ }^{(17,51)}$. Enabling ordering closer to meal times

243 is also likely to better meet patients' immediate preferences and contribute to increased satisfaction.

244 The RS model by mater group in this study facilitates meal delivery within 45 minutes of ordering.

246 A reduction in food costs has been reported as a major benefit of the RS model ${ }^{(27,52,53)}$. This study reported a $28 \%$ reduction in overall food costs with RS compared to TM in the public setting. This is important as healthcare is increasingly delivered within a cost constrained environment and there is a focus on foodservice models to be cost efficient. This reduction in food costs is expected to be due to reductions in production waste through the removal of meal forecasting and bulk cooking in advance, a reduction in non-select meals (whereby a patient is sent a meal that is suitable to their requirements but is not of their choosing) and elimination of replacement meals due to missed, inappropriate or rejected meals. The transition to RS also facilitated a removal of standard snacks ordered for patients on therapeutic diets, including a reduction in oral nutrition supplements, leading to overall reductions in food costs. The integrated menu design allows for higher quality items to be offered to restrictive diets and decreases the need for nutritionally fortified foods, a strategy that is often used to increase nutritional intake in traditional foodservice models ${ }^{(19)}$.

The principal limitation of this study was the retrospective analysis of quality audit data over a 2.5 year period. A randomised controlled trial was not a feasible option in the operative hospital environment, though a strategic pre-post approach within a shorter defined timeframe would be recommended for future RS implementation research. While the two study cohorts were different in terms of age, weight and medical classification, they were closely matched in gender and nutritional requirements.

Collecting meal intake data in the operative hospital environment is difficult and can be a limitation of studies focusing on this outcome measure. Weighing individual meal items before and after patient meals is considered the most accurate measure of intake ${ }^{(54)}$ however this is difficult on a large scale and was not considered feasible for this study. A meal intake observation tool was used to evaluate nutritional intake and plate waste, recording items as a percentage rather than weight and all individual items were assessed in an effort to obtain as accurate nutritional intake data as possible. This tool has also been used in other large studies to measure intake ${ }^{(15,55)}$. 
274 Data collection for nutritional intake and plate waste was collected over a short period of time (4 days per group) and due to differences in ward occupancy rates between 2014 (66\%) as compared with 2017 (87\%) and exclusion criteria and requirement for minimum 24 hours of consecutive order data, a relatively small number of patients were included per subgroup. Future studies should aim to include greater patient numbers to allow sufficient statistical power to analyse effects in subgroups. Patient satisfaction was captured in a one day snapshot of data collection. Whilst there is value in this real time data as opposed to other survey tools which measure satisfaction post discharge,

281 measuring patient satisfaction over a longer time period while they are in hospital may provide information more reflective of their total hospital stay.

\section{Conclusion}

The redesign of hospital foodservice models is increasingly a focus to drive improved patient satisfaction and cost savings, but also to influence clinical outcomes associated with nutritional intake. Systematically measuring key outcomes associated with improvements in foodservice models allows for a balanced, evidence-based approach to foodservice model evaluation and redesign. This is the first time that the comprehensive measurement of key outcomes has been reported for RS in a public hospital setting. The positive outcomes reported suggest that the RS model offers both clinical and cost benefits important to patient and organisational outcomes, irrespective of public or private settings.

\section{References}

1. Marcason W. What is the current direction for hospital room service? Journal of the Academy of Nutrition and Dietetics. Mar 2012;112(3):456.

2. Asase S. Hospital Foodservice and Patient Experience: What's New? Journal of the Academy of Nutrition and Dietetics. 2011;111(8):1121.

3. Wadden K, Wolf B, Mayhew A. Traditional versus room service menu styles for pediatric patients. Canadian Journal of Dietetic Practice and Research Summer 2006;67(2):92-94.

4. Williams $\mathrm{P}$, Walton $\mathrm{K}$. Plate waste in hospitals and strategies for change. e-SPEN, the European e-Journal of Clinical Nutrition and Metabolism. 2011/12/01/ 2011;6(6):e235e241.

5. Ofei KT, Holst M, Rasmussen HH, Mikkelsen BE. How practice contributes to trolley food waste. A qualitative study among staff involved in serving meals to hospital patients. Appetite. 2014/12/01/ 2014;83:49-56.

6. Goonan S, Mirosa M, Spence H. Getting a Taste for Food Waste: A Mixed Methods Ethnographic Study into Hospital Food Waste before Patient Consumption Conducted at Three New Zealand Foodservice Facilities. Journal of the Academy of Nutrition and Dietetics. 2014/01/01/ 2014;114(1):63-71.

7. Mahoney S, Zulli A, Walton K. Patient satisfaction and energy intakes are enhanced by point of service meal provision. Nutrition \& Dietetics. 2009;66(4):212-220. 
8. Hartwell HJ, Edwards JSA, Beavis J. Plate versus bulk trolley food service in a hospital: comparison of patients' satisfaction. Nutrition. 2007/03/01/ 2007;23(3):211-218.

9. Folio D, O'Sullivan-Maillet J, Touger-Decker R. The Spoken Menu Concept of Patient Foodservice Delivery Systems Increases Overall Patient Satisfaction, Therapeutic and Tray Accuracy, and is Cost Neutral for Food and Labor. Journal of the American Dietetic Association. 2002/04/01/2002;102(4):546-548.

10. Dall'Oglio I, Nicolò R, Di Ciommo V, et al. A Systematic Review of Hospital Foodservice Patient Satisfaction Studies. Journal of the Academy of Nutrition and Dietetics. 2015/04/01/ 2015;115(4):567-584.

11. Curtis LJ, Bernier P, Jeejeebhoy K, et al. Costs of hospital malnutrition. Clinical Nutrition. 2017/10/01/ 2017;36(5):1391-1396.

12. Lim S, Chung Benjamin Ong K, Chan Y, Loke WC, Ferguson M, Daniels L. Malnutrition and its impact on cost of hospitalization, length of stay, readmission and 3-year mortality. Vol 312011.

13. Agarwal E, Ferguson M, Banks M, et al. Malnutrition and poor food intake are associated with prolonged hospital stay, frequent readmissions, and greater in-hospital mortality: Results from the Nutrition Care Day Survey 2010. Clinical Nutrition. 2013/10/01/ 2013;32(5):737-745.

14. Freijer K, Tan SS, Koopmanschap MA, Meijers JMM, Halfens RJG, Nuijten MJC. The economic costs of disease related malnutrition. Clinical Nutrition. 2013/02/01/ 2013;32(1):136-141.

15. Hiesmayr M, Schindler K, Pernicka E, et al. Decreased food intake is a risk factor for mortality in hospitalised patients: The NutritionDay survey 2006. Clinical Nutrition. 2009/10/01/ 2009;28(5):484-491.

16. Keller H, Allard J, Vesnaver E, et al. Barriers to food intake in acute care hospitals: a report of the Canadian Malnutrition Task Force. Journal of Human Nutrition and Dietetics. 2015;28(6):546-557.

17. Pullen K, Collins R, Stone T, Carter H, Sadler H, Collinson A. Are energy and protein requirements met in hospital? Journal of Human Nutrition and Dietetics. 2017:n/a-n/a.

18. Elia M, Normand C, Norman K, Laviano A. A systematic review of the cost and cost effectiveness of using standard oral nutritional supplements in the hospital setting. Clinical Nutrition. 2016;35(2):370-380.

19. Mills SR, Wilcox CR, Ibrahim K, Roberts HC. Can fortified foods and snacks increase the energy and protein intake of hospitalised older patients? A systematic review. Journal of Human Nutrition and Dietetics. 2018.

20. Collins J, Porter J. The effect of interventions to prevent and treat malnutrition in patients admitted for rehabilitation: a systematic review with meta-analysis. Journal of Human Nutrition and Dietetics. 2015;28(1):1-15.

21. Navarro DA, Boaz M, Krause I, et al. Improved meal presentation increases food intake and decreases readmission rate in hospitalized patients. Clinical Nutrition. 2016/10/01/ 2016;35(5):1153-1158.

22. Holst M, Beermann $\mathrm{T}$, Mortensen $\mathrm{MN}$, et al. Optimizing protein and energy intake in hospitals by improving individualized meal serving, hosting and the eating environment. Nutrition. 2017/02/01/ 2017;34:14-20.

23. Young A, Allia A, Jolliffe L, et al. Assisted or Protected Mealtimes? Exploring the impact of hospital mealtime practices on meal intake. Journal of Advanced Nursing. 2016;72(7):1616-1625.

24. Maunder K, Lazarus C, Walton K, Williams P, Ferguson M, Beck E. Energy and protein intake increases with an electronic bedside spoken meal ordering system compared to a paper menu in hospital patients. Clinical Nutrition ESPEN. 2015/08/01/ 2015;10(4):e134e139. 
25. Ottrey E, Judi P. Hospital menu interventions: a systematic review of research. International Journal of Health Care Quality Assurance. 2016/02/08 2016;29(1):62-74.

26. Hartwell H, Johns N, Edwards JSA. E-menus-Managing choice options in hospital foodservice. International Journal of Hospitality Management. 2016/02/01/ 2016;53:12-16.

27. McCray S, Maunder K, Krikowa R, MacKenzie-Shalders K. Room Service Improves Nutritional Intake and Increases Patient Satisfaction While Decreasing Food Waste and Cost. Journal of the Academy of Nutrition and Dietetics. 2018;118(2):284-293.

28. CBORD Patient Nutrition Systems, The CBORD Group Ithaca, NY, US. 1996-2017; www.cbord.com/systems/nutrition/ Accessed accessed 24/02/2018., 2018.

29. Nutrition Standards for for Adult Inpatients in NSW Hospitals. Published 2011; https://www.aci.health.nsw.gov.au/_data/assets/pdf_file/0004/160555/ACI_Adult_Nutritio n web.pdf. Accessed 28th August 2017, 2017.

30. Queensland Health Standards for Meals and Menus. Published 2015; https://www.health.qld.gov.au/_data/assets/pdf file/0030/156288/qh-nutritionstandards.pdf. Accessed 28th August 2017, 2017.

31. National Statement on Ethical Conduct in Human Research (Updated May 2015). In: NHMRC, ed. https://www.nhmrc.gov.au/guidelines-publications/e72: Commonwealth of Australia, Canberra; 2007.

32. Agarwal E, Ferguson M, Banks M, Bauer J, Capra S, Isenring E. Nutritional status and dietary intake of acute care patients: results from the Nutrition Care Day Survey 2010. Clinical Nutrition. Feb 2012;31(1):41-47.

33. CBORD Nutrition Service Suite. 1996 - 2017. Accessed 15th March, 2017.

34. CBORD Foodservice Suite. 2017. Accessed 15th March, 2017.

35. AusNut Special Edition database. In: ANZFA, ed. Canberra: Australia New Zealand Food Authority.; 1999.

36. Estimating Energy, Protein \& Fluid Requirements for Adult Clinical Conditions (consensus document). Nutrition Educational Materials Online. 2015; https://www.health.qld.gov.au/nutrition/resources/est_rqts.pdf. Accessed 13th January, 2017.

37. Alix E, Berrut G, Bore M, et al. Energy requirements in hospitalized elderly people. Journal of the American Geriatrics Society. Jul 2007;55(7):1085-1089.

38. Isenring E, Zabel R, Bannister M, et al. Updated evidence-based practice guidelines for the nutritional management of patients receiving radiation therapy and/or chemotherapy.

Nutrition \& Dietetics. 2013;70(4):312-324.

39. Bauer JD, Ash S, Davidson WL, et al. Evidence based practice guidelines for the nutritional management of cancer cachexia. Nutrition \& Dietetics. 2006;63:S3-S32.

40. Gaillard C, Alix E, Sallé A, Berrut G, Ritz P. Energy requirements in frail elderly people: A review of the literature. Clinical Nutrition. 2007/02/01/ 2007;26(1):16-24.

41. Gaillard C, Alix E, Boirie Y, Berrut G, Ritz P. Are elderly hospitalized patients getting enough protein? Journal of the American Geriatrics Society. Jun 2008;56(6):1045-1049.

42. Krenitsky J. Adjusted body weight, pro: evidence to support the use of adjusted body weight in calculating calorie requirements. Nutrition in Clinical Practice. Aug 2005;20(4):468-473.

43. Capra S, Wright O, Sardie M, Bauer J, Askew D. THE ACUTE HOSPITAL FOODSERVICE PATIENT SATISFACTION QUESTIONNAIRE: THE DEVELOPMENT OF A VALID AND RELIABLE TOOL TO MEASURE PATIENT SATISFACTION WITH ACUTE CARE HOSPITAL FOODSERVICES. Foodservice Research International. 2005;16(1-2):1-14.

44. Reserve Bank of Australia. Inflation Calculator. http://www.rba.gov.au/calculator/. Accessed 28th August 2017, 2017.

45. IBM SPSS Statistics software (Version 24.0) [computer program]. Armonk NY: IBM Corp 
46. Wadden K, Wolf B, Mayhew A. Traditional Versus Room Service Menu Styles For Pediatric Patients. Canadian Journal of Dietetic Practice and Research. 2006/07/01 2006;67(2):92-94.

47. Houlston A, Buttery E, Powell B. Cook to order: meeting the nutritional needs of children with cancer in hospital. Paediatr Nurs. May 2009;21(4):25-27.

48. Williams R, Virtue K, Adkins A. Room service improves patient food intake and satisfaction with hospital food. Journal of Pediatric Oncology Nursing. 1998/07/01/ 1998;15(3):183-189.

49. Iff S, Leuenberger M, Rösch S, Knecht G, Tanner B, Stanga Z. Meeting the nutritional requirements of hospitalized patients: An interdisciplinary approach to hospital catering. Clinical Nutrition. 2008/12/01/ 2008;27(6):800-805.

50. Kelly L. Audit of food wastage: differences between a plated and bulk system of meal provision. Journal of Human Nutrition and Dietetics. 1999;12(5):415-424.

51. Naithani S, Thomas JE, Whelan K, Morgan M, Gulliford MC. Experiences of food access in hospital. A new questionnaire measure. Clinical Nutrition. 2009/12/01/ 2009;28(6):625-630.

52. Kuperberg K, Caruso A, Dello S, Mager D. How will a room service delivery system affect dietary intake, food costs, food waste and patient satisfaction in a paediatric hospital? A pilot study. Journal of Foodservice. 2008;19(5):255-261.

53. Kuperberg K, Mager D, Dello S. Transformation to Room Service Food Delivery In a Pediatric Health Care Facility. Canadian Journal of Dietetic Practice and Research. 2009/12/01 2009;70(4):200-203.

54. Fallaize R, Forster H, Macready AL, et al. Online Dietary Intake Estimation: Reproducibility and Validity of the Food4Me Food Frequency Questionnaire Against a 4Day Weighed Food Record. J Med Internet Res. 2014;16(8):e190.

55. Agarwal E, Ferguson $M$, Banks M, Bauer J, Capra S, Isenring E. Nutritional status and dietary intake of acute care patients: Results from the Nutrition Care Day Survey 2010. Clinical Nutrition. 2012/02/01/ 2012;31(1):41-47. 